\title{
La vivienda para sectores de escasos recursos emergente del Presupuesto Participativo en Belo Horizonte
}

\author{
Housing for low-income sectors emerging from the Participatory Budget in Belo \\ Horizonte
}

María Julia Pantaleón, Diego Martín Fiscarelli

Laboratorio de Tecnología y Gestión Habitacional, Facultad de Arquitectura y Urbanismo de la Universidad Nacional de La Plata

juliapantaleon@gmail.com

\section{RESUMEN}

El presente trabajo recupera la experiencia de Presupuesto Participativo en Vivienda desarrollada en Belo Horizonte, Brasil. El objetivo es poner en valor aspectos de la participación ciudadana que posibilitaron el acceso a una vivienda y la ciudad por parte de la población de escasos recursos.

La metodología utilizada comprendió la utilización de material bibliográfico, el relevamiento de informes y planos en el municipio de Belo Horizonte, así como la realización de entrevistas a investigadores y personal técnico que participo de la experiencia.

Los principales resultados de la investigación revelan que el OPH significó un punto de inflexión en el campo de la política habitacional del Belo Horizonte. Si bien representó un avance respecto de la relación Estado-sociedad en la discusión y definición de recursos públicos, desde lo urbano y la arquitectura, los conjuntos habitacionales no diefieren de otros correspondientes a políticas específicas de hábitat desarrollados en America Latina.

\section{ABSTRACT}

The present work recovers the experience of Participatory Budgeting in Housing developed in Belo Horizonte, Brazil. The propose is to highlight aspects of citizen participation that made possible the acces of low-income population to a housing and the city.

The methodology used included the use of bibliographic material, reports and plans from the municipality of Belo Horizonte, as well as interviews to researchers and technical personnel who participated in the experience.

The main results of the investigation reveal that the OPH represented an inflection point in the field of housing policy in Belo Horizonte. Although it represented an advance respect to the relationship of the State and the society in the discussion and definition of public resources, from the urban point of view and the architecture, the housing complexes do not differ from otherssolutions of specific habitat policies developed in Latin America.

PALABRAS CLAVES: hábitat, vivienda, participación, ciudad, políticas públicas

KEY WORDS: habitat, housing, participation, city, public policies

FECHA DE RECEPCIÓN: 31/8/2021| FECHA DE ACEPTACIÓN: 11/10/2021

DOI: http://dx.doi.org/10.30972/arq.0185678 


\section{INTRODUCCIÓN}

La construcción y producción de la ciudad implica la acción de diferentes actores que, a partir de manifestar sus intereses y articular o negociar con otros, definen y/o se apropian de espacios individuales y colectivos. Pirez (1995) explica que la ciudad es un objeto público, donde se encuentran la totalidad de productos diferentes destinados a satisfacer necesidades colectivas e individuales. La misma es producida por diferentes actores (Estado - Sociedad - Económicos Técnicos) que pueden determinar el carácter de la ciudad como bien público con un enfoque redistributivo; o como interés privado, apuntando a la concentración de bienes, poder y recursos en unos pocos actores (Pírez, 1995).

Se puede decir entonces que la ciudad es un objeto de disputa y por tanto en ella se dan procesos de inclusión y exclusión. En este sentido autoras como Arteaga Arredondo (2005) y Signorelli (2016) dan cuenta de las desigualdades presentes en la ciudad, sobre todo en los modos de acceder a bienes y servicios básicos, el hábitat y la vivienda. Las ciudades se densifican, completan y expanden a diferentes ritmos y de diversas formas, por agregación de partes, de forma casi espontánea, conformando un panorama complejo para la intervención urbana (Arteaga Arredondo, 2005). Se observa, una trama urbana dividida que parece "caminar" a distintas velocidades: los sectores excluidos, los que habitan en la periferia en barrios cerrados, o la clase media y alta localizada en los centros de las ciudades (Signorelli, 2016). Se visualiza la complejidad de estos procesos y la existencia de una permanente tensión entre actores por pertenecer a un proyecto de ciudad que los incluya, y el deseo de que el Estado local les brinde las mismas oportunidades de progreso y calidad de vida (Signorelli, 2016).

En este contexto, y focalizando en los sectores de población de escasos recursos económicos, reconocemos las dificulatades que estos experimentan con relación a satisifacer necesidades básicas de vivienda y de ser incluidos en la ciudad. Estos sectores suelen concretar esa demanda a partir de dos modalidades principales. Por un lado, a partir de la autogestión y autoconstrucción de viviendas en lotes vacíos configuando Barrios Populares, Villas o Asentamientos Informales. En segunda instacia, con mayores limitaciones debido al cumplimiento de ciertos requisitos, pueden materializar el acceso a una vivienda a partir de planes o programas de construcción de viviendas impulsados por el Estado (Nacional, Provincial o Municipal). Ambas modalidades generan enclaves con límities físicos perceptibles. Sin embargo, también se generan límites inmateriales relacionados a la pertenencía o no a uno de eso barrios y a las posibilidades de participación en el marco de políticas, programas e instrumentos de gestión y transformación de los territorios.

Es por lo mencionado, que nos interesa reflexionar sobre la contribución que pude hacer el presupuesto participativo (en adelante PP) como instrumento de gestión y producción de la ciudad, el hábitat y vivienda; a partir de la participación de la población en un ámbito de construcción colectiva con el Estado. En el presente artículo, se expone una breve descripción general de la herramienta respecto de su origen y definición, para luego focalizar en el caso específico del PP en Belo Horizonte (Brasil), cuyo proceso se destaca por la emergencia de un PP en vivienda (Orçamento Participativo da Habitação - OPH) además de otras iniciativas que se sostuvieron en el tiempo. Se ejemplifica con dos conjuntos habitacionales producto del OPH, explorando parte de su proceso de gestión, proyecto arquitectónico y estado actual.

\section{METODOLOGÍA}

Las indagaciones propuestas en este artículo intentan reconstruir el proceso de acceso a la vivienda de sectores de la población de escasos recursos económicos, recuperando la experiencia desarrollada en Belo Horizonte a partir la experiencia de $\mathrm{OPH}$. 
El panorama de surgimiento y desarrollo del OPH se construyó a partir de información relvada en la mencionada ciudad en una estadía de investigación de quien suscribe. Se accedió a documentos e informes realizados por el Municipio de Belo Horizonte a través de la empresa urbanizadora URBEL, quienes tienen un registro del estado de las diferentes operatorias desarrolladas, asi como de referentes de la sociedad y de colectivos que participanron de las mismas. Para complementar esta información, se realizaron entrevistas al presidente de la URBEL y a técnicos del municipio que formaron parte del equipo de trabajo del $\mathrm{OPH}$. El contacto con investigadores de la Escola de Arquitetura da Universidad Federal de Minas Gerais (EA UFMG) posibilitó acceso a material audiovisual de recorridos realizados por diferentes conjuntos habitacionales, así como fotografías y bibliografía específica.

La revisión de los conjuntos habitacionales presentados en este trabajo se aboordó a partir de planos facilitados por personal de la URBEL. La revisión de la situación actual de los conjuntos se realizó en función de la documentación brindada por investigadores de la EA - UFMG, análisis de imágenes satelitales y verificación a partir de recorridos virtuales por google earth. Se elaboraron mapas en Sistemas de Información Georreferenciada a partir de información de cada conjunto habitacional ejecutado de $\mathrm{OPH}$, con el fin de posteriorimente incorporar información para futuras investigaciones. En este artículo, la conformación de esa cartografía, permitío tener una primera aproximación a las localizaciones de estos y sistematización de información de cada uno.

\section{DESARROLLO}

EI PP tuvo sus orígenes en Brasil, mas precisamente en Porto Alegre a fines de la década de 1980 y en el marco de transformaciones políticas del país. Sus promotores lo definen como un:

"proceso de democracia directa, voluntaria y universal, donde el pueblo puede discutir y decidir sobre el presupuesto y las políticas públicas. El ciudadano no limita su participación al acto de votar para elegir al Ejecutivo o al Parlamento, sino que también decide las prioridades de gastos y controla la gestión del gobierno" (Sousa Santos, 1998, p. 113)

EI PP es considerado una de las políticas públicas urbanas generadas desde el Sur Global y que logro movilizarse y circular dentro y fuera de su país de origen (Jajamovich, 2017) llegando incluso a Europa y África. Toma presencia en el escenario político y académico de América Latina al final de un largo y poco exitoso ciclo de reformas del Estado que coincide con signos preocupantes de descreimiento en la democracia. Frente a ello, se insinúa la oportunidad de reinventar las relaciones entre el Estado y la sociedad e inscribir a los PP en este horizonte (Cabannes \& Vásconez, 2004).

El ámbito preferencial de implementación del PP es el municipal ya que es el nivel estatal que más fácilmente propicia la relación y acercamiento entre Estado y sociedad. En este sentido la participación es considerada como una alternativa para pensar e intervenir en la construcción, producción y gestión de la ciudad y el hábitat a partir de la complejidad que definen los diversos actores participantes. Es importante subrayar la condición de participación ciudadana ya que remite a una interacción entre Estado y sociedad donde ésta última penetra en cierto punto en las decsiones que generalmente resuelve el primero (Pagani, 2015), además de contemplar la heterogeneidad del universo de actores de la sociedad civil, así como la variedad de campos de política y de momentos del proceso de gestión de las mismas (Rofman \& Foglia, 2015).

Retomando al PP, se lo puede definir como un instrumento de participación y gestión territorial que propone un vínculo entre sociedad y Estado, a partir de la puesta en debate, discusión y definición de una parte de los recursos públicos. I (Cabannes, 2004, 2005; Reese, 2003; Sousa 
Santos, 1998). Como todo instrumento que es parte de las políticas públicas y propone cambios en las modalidades de acción instaladas, posee características para ser valorados de forma positiva o demarcando aspectos limitantes. Dentro de las primeras podemos mencionar: cambio de las condiciones de vida y mejoras infraestructurales en toda la ciudad, en función de propuestas más equitativas en lo territorial y distributiva en lo económico (Merino, 2000:73 en Caruso et al., 2010; Concejo Deliberante, 2008; Prince et al., 2012); fomento de la participación ciudadana (Cabannes, 2005, 2007), la posibilidad de establecer una inversión de prioridades al favorecer o discriminar positivamente a los grupos o sectores más vulnerables (Cabannes, 2005; Carmona \& Martínez, 2014).

Existen diferentes tipos de presupuesto participativo. Por un lado los PP Regionales que suelen abordar a partes 0 a la totalidad de un territorio y lo organizan en asambleas o Regiones Presupuestarias. Por otro, los PP Temáticos donde se definenen temas (medio ambiente, salud, educación, vivienda), o grupos poblacionales específicos (características económicas, de género, de edad, etc) sobre los que focalizará el PP.

\section{Presupuesto Participativo en Belo Horizonte}

El caso que decidimos abordar en este trabajo es la experiencia del PP en Belo Horizonte. Esta ciudad, capital del Estado de Minas Gerais, implementó en 1993 el PP Regional (Orçamento Participativo Regional - OPR), es decir, en todo el municipio sin establecer temas prioritarios. Este proceso fue impulsado por el nuevo alcalde representante del Frente Popular. Los fundamentos para la implementaicón se sustentaron en la fuerte convicción política del nuevo mandatario sobre la participación y la denominada inversión por prioridades que proponía el nuevo instrumento (Blanco, 2002). Durante el primer año se trabajó en el modelo organizativo del OPR con los Coordinadores de Particpación Popular correspondientes a cada una de las 9 adminstraciones locales en las que se organiza el Municpio de Belo Horizonte (Fig. 1).

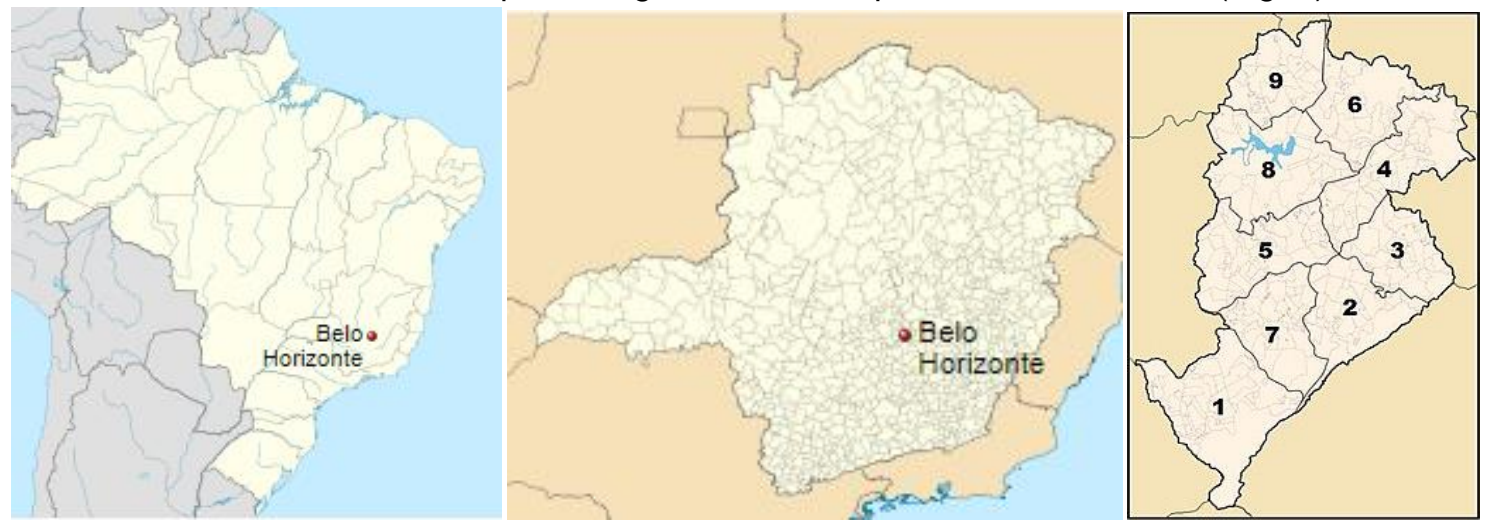

Figura 1: Localización de Belo Horizonte en Brasil y organización administrativa. Fuente: Wikipedia, 2021.

En ese marco, luego de 3 ediciones de OPR la vivienda surgió como una demanda de la población participante en un contexto donde el problema habitacional manifestó un déficit cuantitativo de 55 millones de viviendas (Vadalares, 2004). Los colectivos de lucha por la vivienda, denominados colectivos "Sin-Casa", lograron una participación mayoritaria en las asambleas de los primeros OPR y encontraron en la herramienta una oportunidad de transformación de sus situaciones sociales y materiales (Medeiros, 2019). En respuesta a esta demanda el gobierno local decidió conformar un espacio de discusión de este tema a partir de la creación del Presupuesto Participativo de Vivienda (Orçamento Participativo de Habitação $\mathrm{OPH})$. Es importante destacar que todo este proceso se desarrolló en un momento donde Brasil no contaba con una política habitacional Nacional y en el contexto de transformación del Estado brasilero, donde se intensifica la descentralización de las políticas públicas, municipalizándose 
las obligaciones. Los municipios se vieron con tareas del tamaño de deudas históricas, como la vivienda (Vadalares, 2004).

El OPH, emergió del OPR a partir del posicionamiento de la vivienda como un item de demanda. Las causas principales de la ponderción de este bien como necesidad, se basó, por un lado, en la magnitud del problema habitacional. Por otro lado, este proceso es consecuencia de la articulación de movimientos sociales de lucha por la vivienda y de iniciativas de gestión del Frente Popular de Belo Horizonte. Las iniciativas este último, se formalizaron en el despliegue de actividades dentro del Programa de Autogestión, como ser: la elaboración de un registro de 57 núcleos de Sin-Casa, la organización del $1^{\circ}$ Forum de los Sin-Casa, y la organizaicón y movilización del colectivo en el marco del OPR, dentro del cual consiguieron la aprobación de 365 lotes urbanizados para la posterior contrucción de unidades habitacionales (Saldanha de Oliveira, Morais Castro, \& De Lacerda Godinho, 2007). La participación de los colectivos de SinCasa en el OPR generó al menos dos problemas. El primero referido al tipo de demandas expuestas y que las administraciones regionales no contaban con recursos suficientes para atenderlas de forma simultánea a otras también consideradas prioritarias. El segundo conflicto tuvo que ver con los criterios de destino de las partidas de los recursos financieros del OPR. La definición de prioridades de inversión en virtud de atender al mayor número de personas tornó difícil direccionar recursos para un bien que se caracteriza como de apropiación individual como es la vivienda. En este sentido, el debate estableció que sería posible el direccionamiento de recursos para un bien de apropiación individual, pero de uso colectivos como ser urbanización de favelas, construcción de redes y caminos, etc. En este marco, el OPR continuó su desarrollo en esos términos y emergió el OPH para absorber las demandas de vivienda y constituirse como política municipal.

EI OPH se implementó durante 10 años desde 1996 y su foco fue atender la demanda de familias que que poseían una renta inferior a 5 salarios mínimos. Se previó un financiamiento, con base en la renta per cápita, para un plazo de 15 años, con derechos a la suspensión en caso de desempleo (Vadalares, 2004). La estructura de funcionamiento del OPH difiere de otros tipos de PP. En primer lugar, involucra la acción del Consejo Municipal de Vivienda (CMH) que junto al municipio establece las reglas de funcionamisnto del OPH. En segundo lugar, los participantes del $\mathrm{OPH}$ son familias organizadas en los diferentes núcleos del Moviemiento Sin-Casa registrados en la Secretaría Municipal de Vivienda (SMHAB). Las unidades habitacionales construidas por el $\mathrm{OPH}$ se destinaron a familias que se encuadraban dentro de los criterios propuestos por el $\mathrm{CMH}$ que se basaron en: familias con una renta inferior a 5 salarios mínimos, que habiten en el municipio un mínimo de 2 años, que no hayan participado de otros porgramas de vivienda municipales y que no posean casa propia. Se definen así algunos actores estatales locales y de la sociedad que participaron de la experiencia.

El proceso de implementación del OPH requirió de etapas que ordenaron la experiencia:

1) El municipio define el volumen de recursos financieros a invertir en vivienda popular;

2) EI CMH deliberó sobre: la distribución de los recursos en porcentajes según programa y forma de gestión; los criteios de selección de los núcleos del Movimiento de Sin-Casa a ser atendidos; el número total de familia a ser atendidas por $\mathrm{OPH}$; los criterios para la elección de delegados en el Forum Municipal de OPH.

3) La realización del OPH fue coordinada por la URBEL.

4) En el Forum de OPH, se seleccionaban los núcleos de Sin-Casa a ser contemplados, así como la cantidad de unidades habitacionales que se distribuyeron.

5) A los núclos de los Sin-Casa les correspodía seleccionara los futuros residentes.

\section{Lineas de OPH}

El OPH se inicia con la discusión pública de recursos destinados en un principio a dos acciones: para la compra de terrenos y la construcción de vivienda. Inicialmente se propuso celebrar el 
$\mathrm{OPH}$ con ediciones anuales para luego pasar a una estructura bianual. Se creó un Fondo Municipal de Vivienda Popular que podía recibir partidas de otras esferas gubernamentales y de órganos y agencias financiadoras. En relación con esto las primeras soluciones habitaciales fueron realizadas con fondos de OPH y las siguientes de forma mixta o con la articulaicón de otras operatorias. Las dos líneas de OPH podían materializarse a partir de dos modalidaes de gestión. La urbanización de lotes comprendía intervenciones urbanísticas y se desarrollo vía gestión pública municipal. La construcción de viviendas podía efectuarse por gestión pública, autogestión o algunos casos mixtos. Es importante destacar que los lotes seleccionado para la construcción de los conjuntos habitacionales eran elegidos por las familias de los núcleos de SinCasa que posteriorimente residirían allí (Vadalares, 2004).

\section{Tipologías y estado de obras del OPH}

Entre 1996 y 2003 se aprobaron un total de 4.334 unidades habitacionales de las cuales 2.183 fueron concluidas (Bedê, 2005). De la línea de autogestión 14 fueron los proyectos finalizados con un total de 1.794 unidades de viviendas entregadas. El mapa siguiente (Fig. 2) muestra la localización de los conjuntos habitacionales concluidos por OPH tanto de gestión pública o autogestionados y se descancan dos conjuntos realizados por esta última modalidad de los cuales se obtuvo información sobre el proyecto arquitectónico para poder analizar las tipologías de viviendas, dimensiones, e inserción en el territorio. El Conjunto Habitacional Fernão Dias que se desarrolla en bloques de edificio en altura y el Conjunto Vila Régia que se densenvuelve como viviendas apareadas y se registran al menos 2 configuraciones diferentes de viviendas.

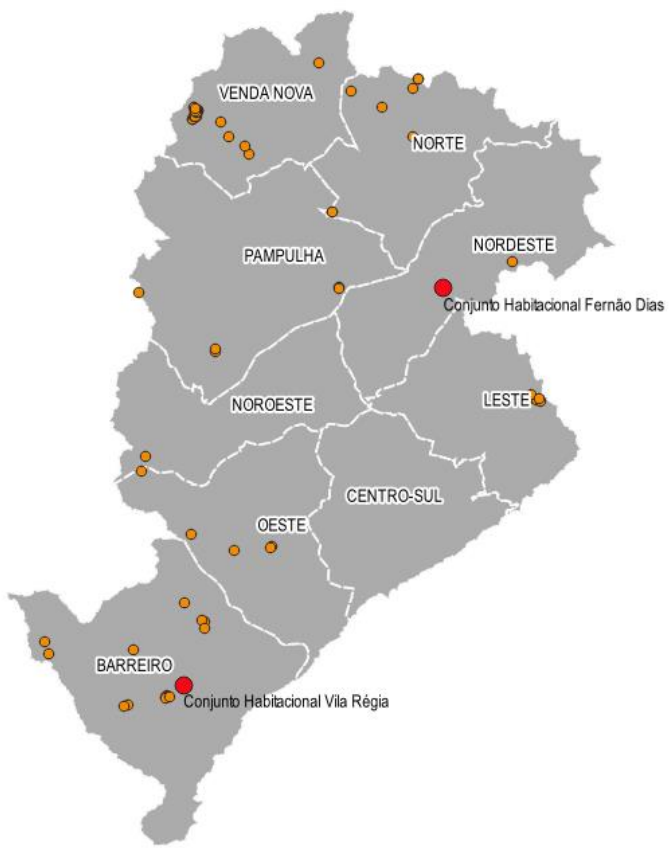

Figura 2: Mapa de localización de los proyectos de OPH ejecutados en diferentes Regionales de BH. Fuente: Elaboración propia en base a información de URBEL 2019.

El Conjunto Habitacional Fernão Dias se ubica en la Regional Nordeste en un predio vacante (Fig. 4). El comienzo de la obra fue en el año 2000 y los recursos financieros fueron de origen municipal a través de la Secretaria Municipal de Habitcao de Belo Horizonte (SMHAB). El núcleo de Sin-Casa que movilizó a las familias se denomina Associação Habitacional e Social da Área Fernão Dias y contó con el apoyo de la asesoría técnica de la Assessoria Social e Pesquisa (ASP). Este conjunto se desarrolló en 3 bloques de vivienda en altura conformados por 9 edificios de 4 niveles (Fig.3). En total se construyeron 144 departamentos. Cada vivienda se desplegó en un solo nivel y tiene aproximadamente $43.50 \mathrm{~m} 2$. En su interior se organiza un esquema simple de cocina, una sala, un baño y 3 dormitorios (Fig. 4). Las unidades se espejan y cada planta tipo 
La vivienda para sectores de escasos recursos emergente del Presupuesto Participativo en Belo Horizonte

Pantaleón, Fiscarelli

de los edificios se contituyen por 4 departamentos. El acceso a cada unidad se efectúa por una escalera central de uso común.
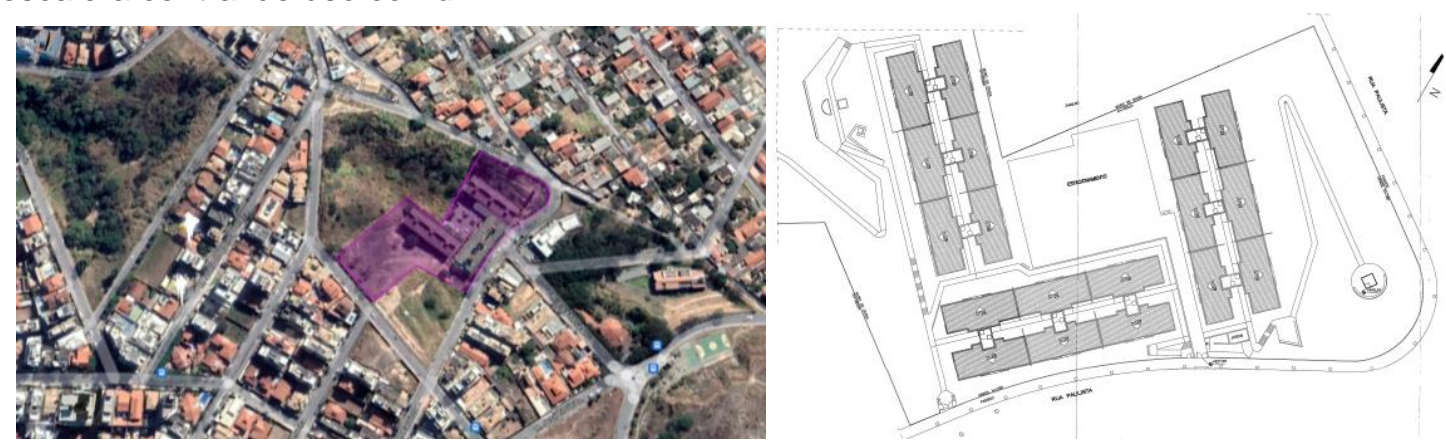

Figura 3: Implantación del Conjunto Fernão Dias y organización de los 3 bloques de vivienda. Fuente: Elaboración propia en base a información de URBEL 2019.

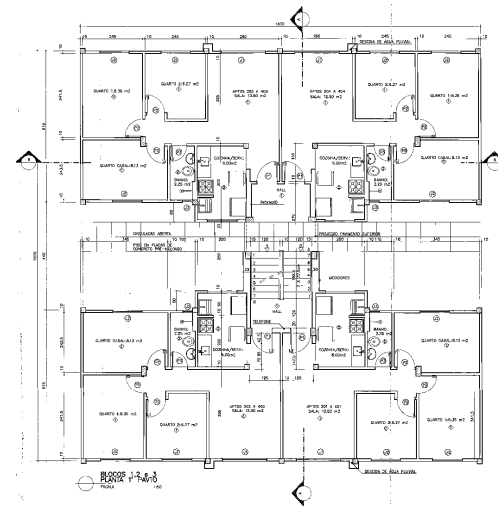

Figura 4: Planta tipo de un edificio del Conjunto Fernão Dias. Se destacan el acceso a cada unidad, las áreas de servicio, la sala y los dormitorios. Fuente: Elaboración propia en base a información de URBEL 2019.

El conjunto habitacional se encuantra cercado en su perímetro con un muro bajo y una estrucutra metálica que define un límite permeable desde la visual en las calles donde se localizan los accesos al barrio. Por el contrario, los frentes que no poseen accesos se constituyen por un muro que a la vez sirve de contenedor del terreno que presenta una gran inclinación. Se puede observar en las imágenes que los edificios se encuentran en buen estado en su exterior y los espacios de uso común como el estacionamiento, las calles internas y la zona verde tienen cierto mantenimiento y un uso adecuado (Fig. 5).

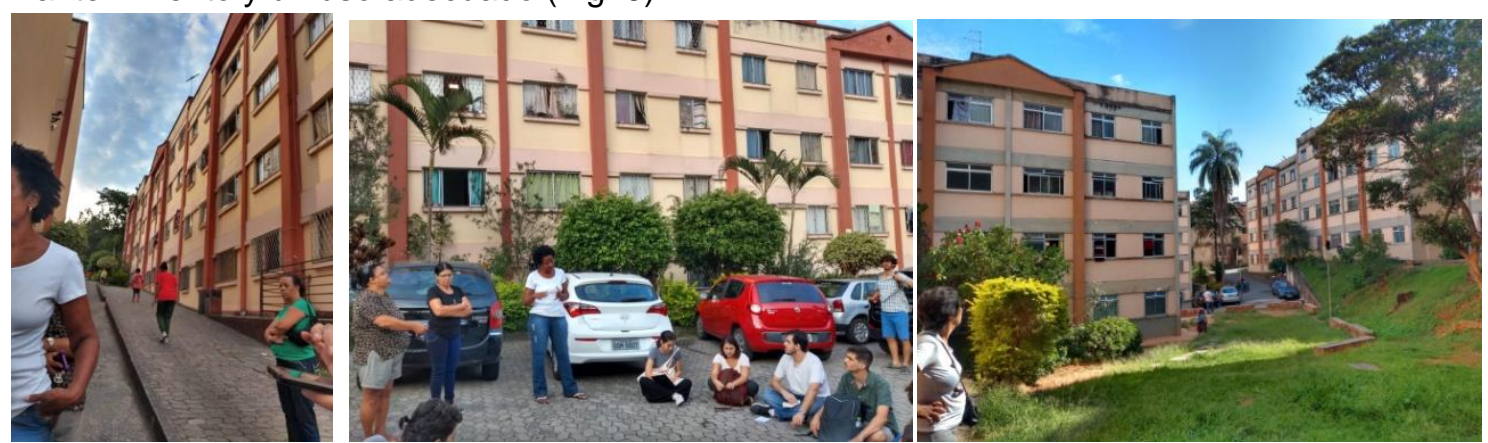

Figura 5: Imágenes espacios comunes Conjunto Fernão Dias. Fuente: Rolezinho de Autogestão (Marina Sanders, 2019).

El Conjunto Habitacional Vila Régia se localiza en la Regional Barreriro, fue producto de la organización de las familias agrupadas bajalo el núcleo de Sin-Casa denominado Associação dos Sem Casas do Bairro Betânia (ASCA). La primera reunión de este colectivo fue en 1991 con la presencia de 500 familias. A partir de su participación en OPH lograron comprar el terreno en el año 1995, se iniciaron las obras un año después y la entrega de las unidades de viviendas se 
La vivienda para sectores de escasos recursos emergente del Presupuesto Participativo en Belo Horizonte

realizó en 1998. Esta iniciativa contó con la participación de algunas familias que trabajaron en el proceso de contrucción, con la colaboración de fuentes remuneradas de trabajo. Esta articulación les permitío agilizar las obras para ser entregada en un año medio. El conjunto se emplaza en una manza como tiras de viviendas agrupadas de forma apareada (Fig.6).
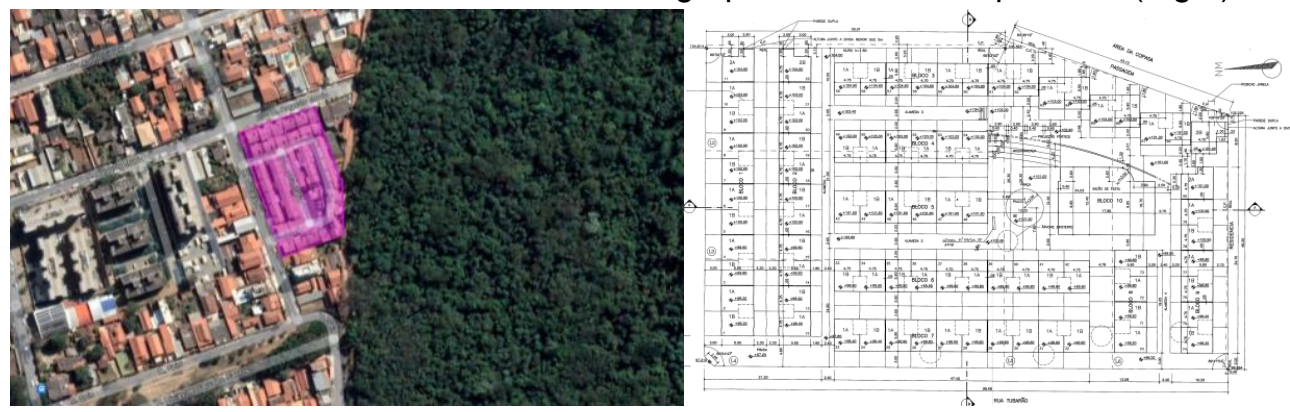

Figura 6: Implantación del Conjunto Vila Régia y planta Conjunto. Fuente: Elaboración propia en base a información de URBEL 2019.

Cada vivienda posee dos niveles y aproximadamente 45,63 m2. Se encuentran 2 tipologías diferentes que se espejan. En las tipologías $1 \mathrm{~A}$ y $1 \mathrm{~B}$ (Fig. 7), se superpone un dormitorio de una sobre el de la otra. Las tipologías $2 \mathrm{~A}$ y $2 \mathrm{~B}$ (Fig. 8) se localizan en algunas esquinas. Todas cuentan, al igual que el Conjunto Fernão Dias, con un baño una cocina, una sala y 3 dormitorios. Se construyeron un toal de 80 viviendas.
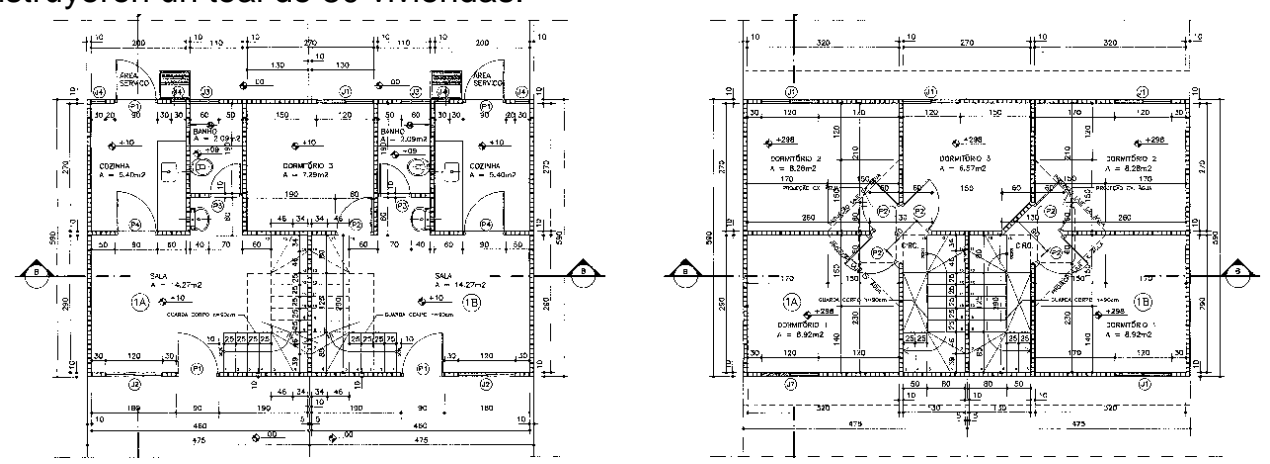

Figura 7: Tipología 1A y 1B Vila Régia. Fuente: Archivo URBEL, 2019.
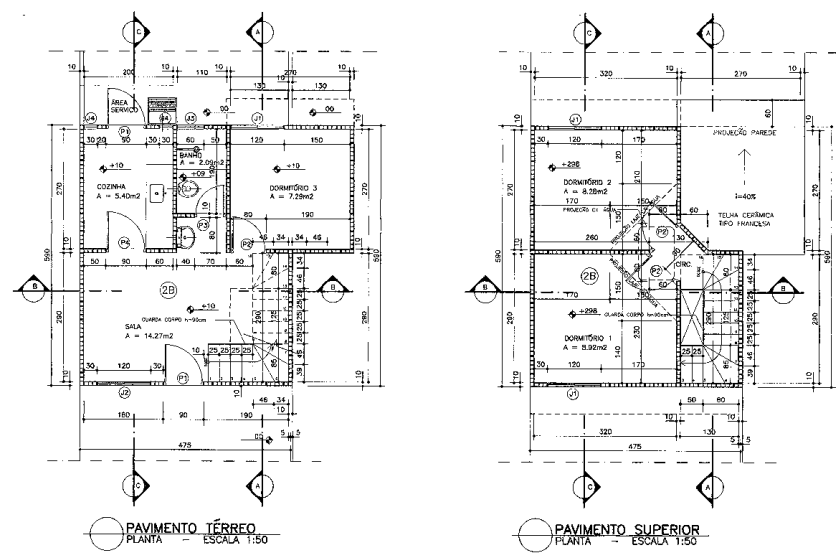

Figura 8: Tipología 2ª y 2B Vila Régia. Fuente: Archivo URBEL, 2019.

La relación con el entorno circundante y el estado general del conjunto es menos favorable que en Fernão Dias. En las imágenes se observa un límite material del conjunto hacia la ciudad a partir de muros de mampostería casi ciegos que poseen una puerta de acceso a cada vivienda y rejas en las escasa aberturas. El espacio central del conjunto se encuentra constituido por un estacionamiento y las calles internas aparecen como de circulación vehicular (Fig. 9). 

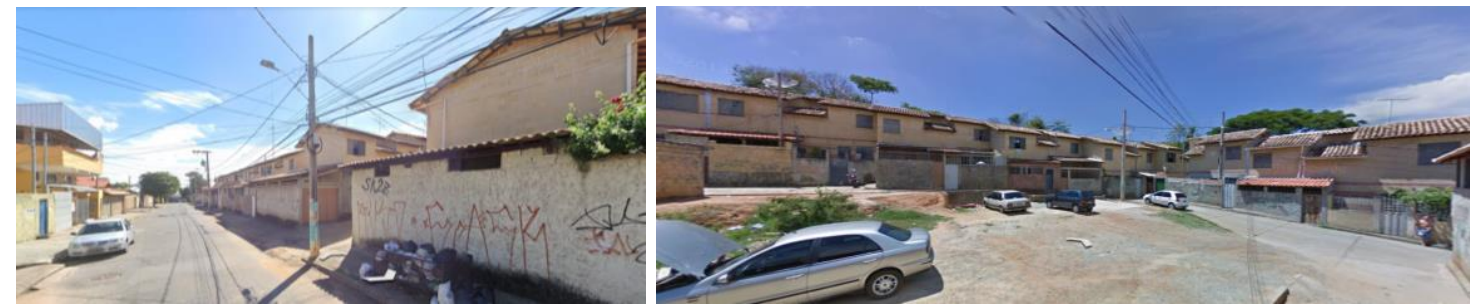

Figura 9: Imágenes exteriores del Conjunto Vila Régia. Fuente: Capturas de Google Street View. Septiembre, 2021.

\section{CONCLUSIONES}

A modo de conclusión podemos decir que el OPH en Belo Horizonte constituyó un primer paso para la constitución de una política pública de vivienda direccionada a atender a los sectores de escasos recursos económicos de esa ciudad. Se destaca en el marco de la vuelta a la democracia de Brasil y los cambios en la reorgainzación del aparato estatal en diferentes niveles, la voluntad polítca de diversos gobiernos locales en implementar un instrumento de participación y gestión del territorio como es el Presupuesto Participativo. Este instrumento viabilizó canales de articulaicón entre sociedad y Estado, y esto se vió reflejado en el caso de Belo Horizonte a partir de la creación de modalidades diferenciadas de PP: atención de demandas a escala ciudad con el OP-Cidade; el OPR, así como necesidades de grupos específicos como las que se nuclearon y dieron origen el $\mathrm{OPH}$.

El OPH puso de manifiesto la fuerza de los colectivos de los Sin-Casa los cuales se apropiaron del instrumento de participacipación de carácter regional. Por otro lado, se verifica la predisposición del Estado de fortalecer a la herramienta y tranformarla en un intrumento focalizado en los sectores más vulnerables, colocándolos así en agenda pública.

Desde la disciplina arquitectura, dentro del OPH se valoran las diferentes modalidades de gestión para el acceso de los grupos Sin-Casa a la vivienda, así como las diferentes tipologías que podían ser materializadas. La revisón de materiales audiovisuales nos permitío recuperar la palabra de algunos de los habitantes de los conjuntos de vivienda de $\mathrm{OPH}$, donde dejaron explicita la conformidad respecto de la operatoria en relación con la posibilidad de acceso a una vivienda y a la participación de algunos vecinos en la construcción de estas.

Respecto a algunos factores limitantes observamos que, como es recurrente en las operatorias de construcción de viviendas estatales, la cantidad de estas no suele satisfacer la demanda cuantitativa. Muchos emprendimientos seleccionados quedaron sin ejecutarse. En el diseño de las unidades y de los conjuntos, se verifican respuestas tipológicas similares a conjuntos desarrollados en otras ciudades latinoamericas. El espacio urbano circundante dista mucho de propuestas amigables y que generen inclusión urbana. Esto continúa siendo agenda pendiente de las políticas habitacionales.

Como última reflexión, el proceso del $\mathrm{OPH}$ en reuniones bianuales de puesta en común y acuerdos, sumado a demoras de respuesta del Estado en relación a la construcción de las viviendas y el surgimiento de otros programas de atención a la demanda de vivienda de los sectores de escasos recursos, culminó con la desapricón del OPH como política habitacional.

\section{BIBLIOGRAFÍA}

Arteaga Arredondo, I. (2005). De Periferia a Ciudad Consolidada. Revista Bitácora Urbano Territorial, 9, 1-15. Retrieved from http://www.redalyc.org/articulo.oa?id=74800909

Bedê, M. M. C. (2005). Trajetória da formulação e implementação da política habitacional de Belo Horizonte na gestão da Frente BH Popular (1993-1996). 302.

Blanco, I. (2002). Presupuestos participativos y democracia local: una comparación entre las 
experiencias brasileñas y españolas. VII Congreso Internacional Del CLAD Sobre La Reforma Del Estado y de La Administración Pública, 8-11.

Cabannes, Y. (2004). Presupuesto Participativo y finanzas locales. In Programa de Gestión Urbana PGU -ALC / UN - HABITAT (Vol. 137). Retrieved from http://www.rosario.gov.ar/sitio/verArchivo?id=4875\&tipo=objetoMultimedia

Cabannes, Y. (2005). Presupuesto Participativo y finanzas locales - segunda versión ampliada.

Cabannes, Y. (2007). Instrumentos de articulación entre Presupuesto Participativo y Ordenamiento Territorial. In Algo está pasando en Europa... V Jornadas Internacionales sobre Presupuestos Participativos.

Carmona, R., \& Martínez, C. (2014). Luces y sombras del presupuesto participativo en la región metropolitana de Buenos Aires. Región $Y$ Sociedad, 26(61). https://doi.org/10.22198/rys.2014.61.a66

Caruso, P., Páez, W., \& Adaro, C. (2010). Fortalecimiento y asistencia del gobierno nacional a los gobiernos locales en la implementación del Presupuesto Participativo. Biblioteca.Municipios.Unq.Edu.Ar, $1-15 . \quad$ Retrieved from http://biblioteca.municipios.unq.edu.ar/modules/mislibros/archivos/CarusoRedMuni2010_2 .pdf

Concejo Deliberante, M. de L. P. (2008). Decreto Municipal N²54/2008. La Plata.

Jajamovich, G. (2017). América Latina y las asimetrías de poder en abordajes sobre producción y circulación de políticas y teorías urbanas. Revista Quid 16, (8), 160-173.

Pagani, M. L. (2015). "Vos proponés, vos decidís." Retrieved from http://sedici.unlp.edu.ar/handle/10915/50125

Pírez, P. (1995). Actores sociales y gestión de la ciudad. Ciudades, (28), 1-12.

Prince, A., Jolias, L., \& Doria, A. (2012). Presupuesto participativo en Argentina: análisis de su evolución y estudio de caso. XI Seminario de RedMuni: "Repensando La Agenda Local."

Reese, E. (2003). Instrumentos de gestión urbana, fortalecimiento del rol del municipio y desarrollo con equidad. Lincoln Institute of Land Policy.

Rofman, A., \& Foglia, C. (2015). La participación ciudadana local en la historia argentina reciente (de los' 90 a la actualidad): asistencia, movilización, institucionalización. Revista Estado y Políticas Públicas, (5), 41-61. Retrieved from http://repositorio.flacsoandes.edu.ec/handle/10469/8920

Saldanha de Oliveira, P. R., Morais Castro, J. F., \& De Lacerda Godinho, M. H. (2007). Orçamento Participativo da Habitação em Belo Horizonte - o caso do Conjunto Granja de Freitas III. In A. N. de T. do A. C. - \& ANTAC (Eds.), Habitação social nas metrópoles brasileras. Porto Alegre.

Signorelli, G. V. (2016). El rol de los territorios populares en el presupuesto participativo de las ciudades de porto alegre y rosario. America Latina Hoy, 72, 103-128. https://doi.org/10.14201/alh201672103128

Sousa Santos, B. (1998). Presupuestación participativa. Hacia una democracia redistributiva.

Vadalares, M. G. (2004). Presupuesto Participativo y Vivienda. Brasil - Belo Horizonte. La Era Urbana, 42(1), 339. 
